\title{
Correction to: Bridging the research to practice gap: a systematic scoping review of implementation of interventions for cancer-related fatigue management
}

\author{
Oluwaseyifunmi Andi Agbejule ${ }^{1 *}$, Nicolas H. Hart ${ }^{1,2,3}$, Stuart Ekberg ${ }^{1}$, Bogda Koczwara ${ }^{4}$, Rahul Ladwa5, ${ }^{5,6}$,
} Camilla Simonsen ${ }^{1,5}$, Elizabeth P. Pinkham ${ }^{1,5,7}$ and Raymond Javan Chan ${ }^{1,5}$

\section{Correction to: BMC Cancer 21, 809 (2021) https://doi.org/10.1186/s12885-021-08394-3}

Following publication of the original article [1], the authors identified an error in the author name of Bogda Koczwara. The given name and family name were erroneously transposed.

The incorrect author name is: Koczwara Bogda

The correct author name is: Bogda Koczwara

The author group has been updated above and the original article [1] has been corrected.

\footnotetext{
Author details

${ }^{1}$ Cancer and Palliative Care Outcomes Centre, School of Nursing, Queensland University of Technology (QUT), N Block, Kelvin Grove Campus, Kelvin Grove, Queensland 4059, Australia. ${ }^{2}$ Exercise Medicine Research Institute, Edith Cowan University, Perth, Western Australia 6027, Australia. ${ }^{3}$ Institute for Health Research, University of Notre Dame Australia, Fremantle, Western Australia 6959, Australia. ${ }^{4}$ Flinders University and Flinders Medical Centre, Flinders Drive, Bedford Park, South Australia 5048, Australia. ${ }^{5}$ Princess Alexandra Hospital, Metro South Hospital and Health Services, Woolloongabba, Queensland 4102, Australia. ${ }^{6}$ School of Medicine, University of Queensland, St Lucia, Queensland 4072, Australia. ${ }^{7}$ School of Health and Behavioural Science, University of Queensland, St Lucia, Queensland 4072, Australia.
}

Published online: 02 August 2021

\section{Reference}

1. Agbejule OA, Hart NH, Ekberg S, Koczwara B, Ladwa R, Simonsen C, et al. Bridging the research to practice gap: a systematic scoping review of implementation of interventions for cancer-related fatigue management. BMC Cancer. 2021;21(1):809. https://doi.org/10.1186/s12885-021-08394-3.

The original article can be found online at https://doi.org/10.1186/s12885021-08394-3.

*Correspondence: agbejulo@qut.edu.au

${ }^{1}$ Cancer and Palliative Care Outcomes Centre, School of Nursing, Queensland University of Technology (QUT), N Block, Kelvin Grove Campus, Kelvin Grove, Queensland 4059, Australia

Full list of author information is available at the end of the article

(c) The Author(s). 2021 Open Access This article is licensed under a Creative Commons Attribution 4.0 International License, which permits use, sharing, adaptation, distribution and reproduction in any medium or format, as long as you give appropriate credit to the original author(s) and the source, provide a link to the Creative Commons licence, and indicate if changes were made. The images or other third party material in this article are included in the article's Creative Commons licence, unless indicated otherwise in a credit line to the material. If material is not included in the article's Creative Commons licence and your intended use is not permitted by statutory regulation or exceeds the permitted use, you will need to obtain permission directly from the copyright holder. To view a copy of this licence, visit http://creativecommons.org/licenses/by/4.0/ The Creative Commons Public Domain Dedication waiver (http://creativecommons.org/publicdomain/zero/1.0/) applies to the data made available in this article, unless otherwise stated in a credit line to the data. 